\title{
Mitochondria-targeted antioxidant MitoQ ameliorates experimental mouse colitis by suppressing NLRP3 inflammasome-mediated inflammatory cytokines
}

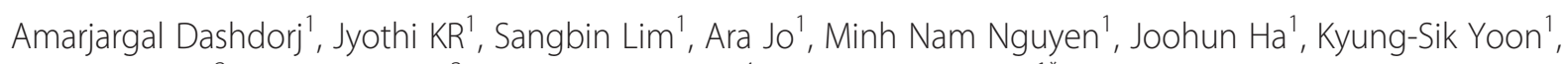
Hyo Jong Kim², Jae-Hoon Park ${ }^{3}$, Michael P Murphy and Sung Soo Kim ${ }^{1 *}$

\begin{abstract}
Background: MitoQ is a mitochondria-targeted derivative of the antioxidant ubiquinone, with antioxidant and anti-apoptotic functions. Reactive oxygen species are involved in many inflammatory diseases including inflammatory bowel disease. In this study, we assessed the therapeutic effects of MitoQ in a mouse model of experimental colitis and investigated the possible mechanisms underlying its effects on intestinal inflammation.
\end{abstract}

Methods: Reactive oxygen species levels and mitochondrial function were measured in blood mononuclear cells of patients with inflammatory bowel disease. The effects of MitoQ were evaluated in a dextran sulfate sodium-induced colitis mouse model. Clinical and pathological markers of disease severity and oxidative injury, and levels of inflammatory cytokines in mouse colonic tissue were measured. The effect of MitoQ on inflammatory cytokines released in the human macrophage-like cell line THP-1 was also analyzed.

Results: Cellular and mitochondrial reactive oxygen species levels in mononuclear cells were significantly higher in patients with inflammatory bowel disease $(P<0.003$, cellular reactive oxygen species; $P<0.001$, mitochondrial reactive oxygen species). MitoQ significantly ameliorated colitis in the dextran sulfate sodium-induced mouse model in vivo, reduced the increased oxidative stress response (malondialdehyde and 3-nitrotyrosine formation), and suppressed mitochondrial and histopathological injury by decreasing levels of inflammatory cytokines IL-1 beta and IL-18 ( $P<0.001$ and $P<0.01$ respectively). By decreasing mitochondrial reactive oxygen species, MitoQ also suppressed activation of the NLRP3 inflammasome that was responsible for maturation of IL-1 beta and IL-18. In vitro studies demonstrated that MitoQ decreases IL-1 beta and IL-18 production in human THP-1 cells.

Conclusion: Taken together, our results suggest that MitoQ may have potential as a novel therapeutic agent for the treatment of acute phases of inflammatory bowel disease.

Keywords: Dextran sulfate sodium, Interleukin-1 beta, Interleukin-18, MitoQ;NLRP-3 inflammasome, Reactive oxygen species

\footnotetext{
* Correspondence: sgskim@khu.ac.kr

'Department of Biochemistry and Molecular Biology, School of Medicine,

Kyung Hee University, Seoul 130-701, Republic of Korea

Full list of author information is available at the end of the article
} 


\section{Background}

Inflammatory bowel disease (IBD) is a chronic relapsing inflammatory disorder of the intestine that comprises two major clinical forms, namely, ulcerative colitis (UC) and Crohn's disease (CD). Clinical features consist of diarrhea, abdominal pain, rectal bleeding and weight loss. The complications observed in colonic manifestations are bowel strictures, obstruction, abscess formation and perforation. In addition, IBD leads to extra-colonic inflammatory manifestations in many organs including the joints, eyes, skin and liver [1]. Conventional medications such as corticosteroids and immune-modulators are the first line of therapy for IBD. However, remission from corticosteroids is only maintained for a short period, and treatment impairs general immunity. A recently developed monoclonal antibody targeting TNF- $\alpha$ shows efficacy in inducing and maintaining remission, but has serious side effects, including an increased risk of infection. Moreover, some patients do not show adequate responses [2,3]. Systematic review of population-based studies between 1950 and 2010 shows that prevalence and incidence of IBD are dramatically increasing throughout the world [4]. Therefore, there is a need to develop safer and more effective therapies for IBD.

The exact etiology of IBD is still not fully understood, but dysfunctional immunoregulation of the gut plays a crucial role in the pathogenesis of IBD [5]. IL-1 beta and IL-18 are the major pro-inflammatory cytokines that promote activation of both the innate and adaptive immune responses [6,7]. Hypoxia-induced transcription factor forkhead box p3 (Foxp3) enhances regulatory T cells, which are essential for immune tolerance and play a crucial role in the limitation of excessive helper $\mathrm{T}$ cells induction and inflammatory response [8]. But, inflammatory cytokines including IL-1 beta inhibit Foxp3 function, induce differentiation of helper $\mathrm{T}$ cells, and can cause $\mathrm{T}$ cellmediated inflammation $[9,10]$. High levels of IL-1 beta and IL-18 expression in patients with IBD $[11,12]$ and their correlation with disease activity [13] have been well described, and indicate that these cytokines play an important role in promoting localized inflammation in IBD. IL-1 beta and IL-18 are expressed as inactive precursors and activated after cleavage by the NACHT, LRR and PYD domains-containing protein 3 (NLRP3) inflammasome, whose mutations have been associated with $\mathrm{CD}$ [14]. The NLRP3 inflammasome is a multi-protein, caspase-1 activating complex, and its dysregulation is strongly associated with many inflammatory diseases [15]. Several reports have shown that the NLRP3 inflammasome plays a pathological role in experimental colitis [16,17], and that activation of the NLRP3 inflammasome is mediated by mitochondrial reactive oxygen species (mtROS) [18-20]. Moreover, many studies have shown that ROS mediate intestinal tissue injury, and that administration of antioxidants or overexpression of antioxidant enzymes leads to amelioration of experimental colitis. Furthermore, a strong association between oxidative stress and IBD has been observed in many human studies [21]. A possible role of mitochondrial dysfunction in the pathogenesis of IBD was reported in clinical cases $[22,23]$, and these data also suggested that mtROS play a role in the pathogenesis of IBD.

MitoQ is an orally available mitochondria-targeted derivative of the antioxidant ubiquinone. MitoQ comprises a lipophilic triphenylphosphonium (TPP) cation that drives rapid permeation of phospholipid bilayers and leads to an accumulation within mitochondria. In the mitochondrial matrix, MitoQ is continually reduced by the respiratory chain to its active form and protects mitochondria from oxidative damage. Due to the characteristic of selective accumulation and continual recycling within mitochondria, MitoQ has been demonstrated in vitro and in vivo to be protective against many oxidative damage-related pathologies, including ischemia-reperfusion injury [24], cardiovascular diseases [25,26], ethanol-dependent hepatosteatosis [27] and sepsis [28]. MitoQ has successfully been tested in phase I and phase II clinical trials and shown to be effective against liver damage in patients with hepatitis $\mathrm{C}$ infection [29]. Importantly, these clinical trials showed that MitoQ has no severe adverse effects.

In this study, we hypothesized that MitoQ might decrease the excessive activation of the NLRP3 inflammasome, and thus attenuate acute phases of IBD. Therefore, we tested if MitoQ can function as a therapeutic agent to treat acute colonic injury in a mouse model of dextran sulfate sodium (DSS)-induced colitis.

\section{Methods}

\section{Peripheral blood mononuclear cells}

Blood samples were obtained from seven patients with active CD (four men, three women), seven with active UC (five men, two women) and 14 healthy volunteers (five women, nine men) as normal controls. Blood samples were carefully layered over 3 to $5 \mathrm{ml}$ of polymorphonuclear leukocyte isolation medium (Cedarlane Laboratories, Hornby, ON, Canada). Samples were centrifuged at $450 \mathrm{~g}$ for 30 minutes at $18^{\circ} \mathrm{C}$. At the end of centrifugation, the top band that consisted of mononuclear cells (MNC) was harvested with a Pasteur pipette, repeatedly washed with Hank's balanced salt solution and then subjected to ROS levels measurement and preparation of mitochondrial proteins. This study was approved by the Institutional Review Board of the Kyung Hee University of Korea, College of Medicine. All participants signed a written informed consent form before any protocol-specific procedure was carried out.

\section{Reactive oxygen species analysis}

ROS levels were measured with the fluorescent probes 2', $7^{\prime}$-dichlorofluoresceindiacetate (DCF-DA) and MitoSOX. 
Cells were loaded with $10 \mu \mathrm{M}$ of DCF-DA or MitoSOX at $37^{\circ} \mathrm{C}$ for 30 minutes and washed with $1 \mathrm{ml}$ PBS. Fluorescence was determined with excitation at $488 \mathrm{~nm}$ and emission at $525 \mathrm{~nm}$ by flow cytometer (FACSCalibur; Becton-Dickinson, Franklin Lakes, NJ, USA).

\section{Preparation of mitochondrial fraction and mitochondrial proteins}

Preparation of mitochondrial fraction and proteins were performed as previously described [30]. The isolated mitochondria were subjected to mitochondrial electron transport chain complex expression measurements as previously described [31].

\section{Animals}

Female Balb/c (wild type; WT) mice (6 to 7 weeks of age; weighing 18 to $20 \mathrm{~g}$ ) were purchased from Central Lab. Animal, Inc. (Seoul, Korea). Four to five animals were housed per cage and fed standard mice chow pellets, had access to tap water supplied in bottles, and were acclimatized 7 days before they went into experiments. The experimental protocol was approved by the Institutional Animal Care and Use Committee of Kyung Hee University (Seoul, Korea).

\section{Induction of colitis and treatment}

DSS(molecular weight, 36,000-50,000) was purchased from MP Biomedicals (Illkirch, France). Mice were divided into four groups: control group (WT), DSS-induced colitis group (WT+DSS), DSS with decyltriphenylphosphonium bromide (dTPP)-treated group (DSS+dTPP), and DSS with MitoQ-treated (DSS+MitoQ) group. Considering the fast recovery of DSS-induced colitis in mice after DSS withdrawal [32], we gave $4 \%$ DSS in their drinking water from day 0 to day 7 , followed by $1 \%$ DSS for maintaining pathology as described previously [33]. None of the mice in this study died before termination of the experiment at day 21 . Control mice were given tap water. MitoQ and dTPP were administered orally at a final concentration of $500 \mu \mathrm{M}$ from day 7 for 14 days until the end of experiments [34]. All compounds were dissolved in water and given fresh every third day. Clinical scores of colitis, such as weight change and colorectal bleeding, were observed. Mice were then sacrificed and the colons were removed, cleaned, and length was measured.

\section{Isolation of peritoneal macrophages}

Mice were anesthetized with isoflurane, sacrificed by cervical dislocation, and injected with $10 \mathrm{ml}$ of PBS. After 30 seconds of abdominal massaging, peritoneal lavage was performed. Collected peritoneal lavage was centrifuged and plated in 60 well plates and incubated for 2 hours. Adherent cells were analyzed in subsequent experiments.

\section{Histological analysis}

Distal colonic sections of $1.5 \mathrm{~cm}$ were fixed in $10 \%$ neutralbuffered formalin, processed for paraffin embedding, sectioned at $5 \mu \mathrm{m}$ and stained with hematoxylin and eosin according to standard protocols. Histological scoring was performed in a blinded fashion by a pathologist using a combined score of inflammatory cell infiltration (score 0 to 3 ) and tissue damage (score 0 to 3 ). Focally increased numbers of inflammatory cells in the lamina propria were scored as 1 , confluence of inflammatory cells extending into the submucosa as 2, and transmural extension of the infiltrate as 3 . For tissue damage, discrete lymphoepithelial lesions were scored as 1 , mucosal erosions as 2 , and extensive mucosal damage or extension through deeper structures of the bowel as 3 . The two equally measured sub-scores were added and the combined histological colitis severity ranged from 0 to 6 .

\section{Transmission electron microscopy}

Colon tissues were fixed in fixative solution (2\% glutaraldehyde and $1 \%$ formaldehyde in $0.1 \mathrm{M}$ sodium cacodylate buffer, pH 7.4) for 2 hours and washed with sodium cacodylate buffer. After fixing with $1 \%$ osmium tetraoxide, tissues were washed and dehydrated by replacement of ascending series of alcohol. Tissues were embedded in epon and propylene oxide (1:1) and sectioned using an ultramicrotome (Reichert Ultracut S, Leica Microsystems, Wetzlar, Germany). Ultrastructural changes were observed using a transmission electron microscope (Zeiss EM 902A, Oberkohen, Germany) under $80 \mathrm{kV}$.

\section{Immunohistochemical analysis}

Colons were fixed in $10 \%$ buffered formalin, dehydrated, embedded in paraffin and sectioned at $5 \mu \mathrm{m}$ slices. Sections were stained with anti-malondialdehyde antibody (Genox Corp., Baltimore, MD, USA) or anti-nitrotyrosine antibody (Cayman Chemical, Ann Arbor, MI, USA) overnight, followed by incubation with biotin-labeled anti-rabbit antibody. Both sections were counterstained by hematoxylin (Gene Tex, Irvine, California, USA) and mounted with (Vector laboratories, Burlingame, CA, USA). The immunostained sections were visualized with an EnVision Detection Kit (Dako, CA, USA).

\section{Cytokine measurement}

Colon homogenates were centrifuged at $15,000 \mathrm{rpm}$ for 15 minutes. The amounts of IL- 1 beta and IL- 18 were quantified by ELISA (MBL and R\&D Systems, Minneapolis, MN, USA) according to the manufacturer's protocol.

\section{Reverse transcription-PCR}

For the analysis of IL-1 beta and IL-18 mRNA, total RNA was extracted from colon tissue using Trizol reagent (Invitrogen, Carlsbad, CA, USA) and $1 \mu \mathrm{g}$ was amplified using the following specific primers: IL-1 beta forward, 
5'-ACAACTGCACTACAGGCTCC-3', and reverse, 5'CTCTGCTTGTGAGGTGCTGA-3'; IL-18 forward, 5'-GGCTGCCATGTCAGAAGACT-3', and reverse, 5'GTCTGGTCTGGGGTTCACTG-3'; GAPDH forward, 5'-CAACTTTGGCATTGTGGAAGGG-3', and reverse, 5'ACACATTGGGGGTAGGAACA-3'.

The amplified products were visualized on a $1 \%$ agarose gel, and the amplified GAPDH fragment was used as an internal control for RT-PCR.

\section{Cell culture}

Human THP-1 cells were grown in Roswell Park Memorial Institute medium, supplemented with $10 \%$ fetal bovine serum, 100 units $/ \mathrm{ml}$ of penicillin and $100 \mu \mathrm{g} / \mathrm{ml}$ of streptomycin. Cells were differentiated with $100 \mathrm{nM}$ phorbol 12-myristate 13-acetate (Sigma Chemical Co, St Louis, MO, USA) for 24 hours. Cells were then treated with $\mathrm{H}_{2} \mathrm{O}_{2}$ ( $5 \mathrm{mM}$ ) for 6 hours with or without MitoQ (50 to $150 \mathrm{nM}$ ). Before collecting supernatants, cells were subsequently stimulated by ATP for 30 minutes. Supernatants and cell lysates were analyzed in subsequent experiments.

\section{Immunoprecipitation and western blotting analysis}

Immunoprecipitation (IP) was performed as described previously [35]. The IP samples and colon homogenates were separated using $8 \%$ to $13.5 \%$ SDS-polyacrylamide gels. The following primary antibodies were used: each subunit of mitochondrial complexes (MitoScience, Eugene, OR, USA), NLRP3 (mouse monoclonal; Adipogen, Inc., Incheon, Korea), apoptosis-associated speck-like protein containing a CARD (ASC; rabbit monoclonal, Adipogen, Inc.), caspase-1 (rabbit polyclonal; Santa Cruz Biotechnology, Santa Cruz, CA, USA), IL-18 (mouse monoclonal; R\&D Systems), IL-1 beta (rabbit polyclonal; BioVision, Inc., Milpitas, CA, USA), thioredoxin (TRX;rabbit monoclonal; AbFrontier, Seoul, Korea), TRX interacting protein (TXNIP; goat monoclonal; MBL International, Woburn, MA, USA) and actin (goat polyclonal; Abcam, Cambridge, MA, USA). Blots were washed with Tris-buffered saline with Polyethylene glycol sorbitan monolaurate 20 and developed with enhanced chemiluminescence reagents (Santa Cruz Biotechnology).

\section{Statistical analysis}

Results were expressed as mean \pm standard error (SE). Error bars represent the mean $\pm \mathrm{SE}$ of at least three independent experiments. The difference between two mean values was analyzed using a Student's t-test. The difference was considered statistically significant when $P<0.05$.

\section{Results}

Reactive oxygen species levels increase in the mononuclear cells of patients with inflammatory bowel disease

To determine whether there was an increase in ROS during IBD, we measured ROS levels via flow cytometry using the ROS probes DCF-DA and MitoSOX in the MNC of patients with IBD. Blood samples were obtained from patients before and after treatment. Patients received standard drugs in combination, as illustrated in Additional file 1: Table S1. Interestingly, ROS levels, as measured by both probes, were increased in the MNC of patients with active IBD. However, ROS levels were significantly decreased in patients in clinical remission (Figure 1A). To assess whether the changes in ROS levels were associated with changes in mitochondrial function, we checked the expression levels of mitochondrial electron transport chain (mtETC) complex subunits. As shown in Figure 1B, expression levels of mtETC complexes were increased during IBD, but decreased after treatment and clinical remission was achieved. We also checked induction of manganese superoxide dismutase, which responds to elevated oxidative stress in mitochondria. The expression level of MnSOD was increased during IBD and decreased after treatment. Voltage dependent anion channel was used to verify that mitochondrial proteins were equally loaded for western blotting analysis. From these results, we concluded that changes in mitochondrial function and mtROS levels correlate with IBD.

\section{MitoQ attenuates dextran sulfate sodium-induced colitis}

Since elevated ROS levels and changes in mitochondrial function seemed to correlate with the pathogenesis of IBD, we investigated the therapeutic effect of MitoQ on DSS-induced mouse colitis. To induce severe colitis, we treated mice with $4 \%$ DSS for 7 days and then 1\% DSS for another 14 days in their drinking water. MitoQ or dTPP was administered from day 7 until the end of the experiment (Figure 2A). dTPP, which contains the same lipophilic cation as MitoQ but lacks antioxidant activity, was used as a negative control. Body weight loss was significantly increased in mice with DSS-induced colitis, and treatment with dTPP did not reverse this weight loss. However, mice with DSS-induced colitis treated with MitoQ gained weight similar to control mice (Figure 2B). The colon length shortening and bloody stool score were also significantly increased in mice treated with DSS or DSS+dTPP. Once again, MitoQ administration inhibited the DSS-induced bloody stool and decreased the colon length shortening (Figure 2C,D). Distal colonic sections from DSS and DSS+dTPP-treated mice revealed multifocal inflammatory cell infiltration and edema with crypt and epithelial cell destruction and ulceration. By contrast, no mucosal inflammation was observed in colonic sections of DSS+MitoQ-treated mice (Figure 2E,F). Colitis score was also significantly lower in MitoQ-treated colitis mice than in the DSS and DSS+dTPP-treated mice (Figure 2G). These data reveal that MitoQ inhibits clinical and histological changes in the colon associated with DSS-induced colitis. 

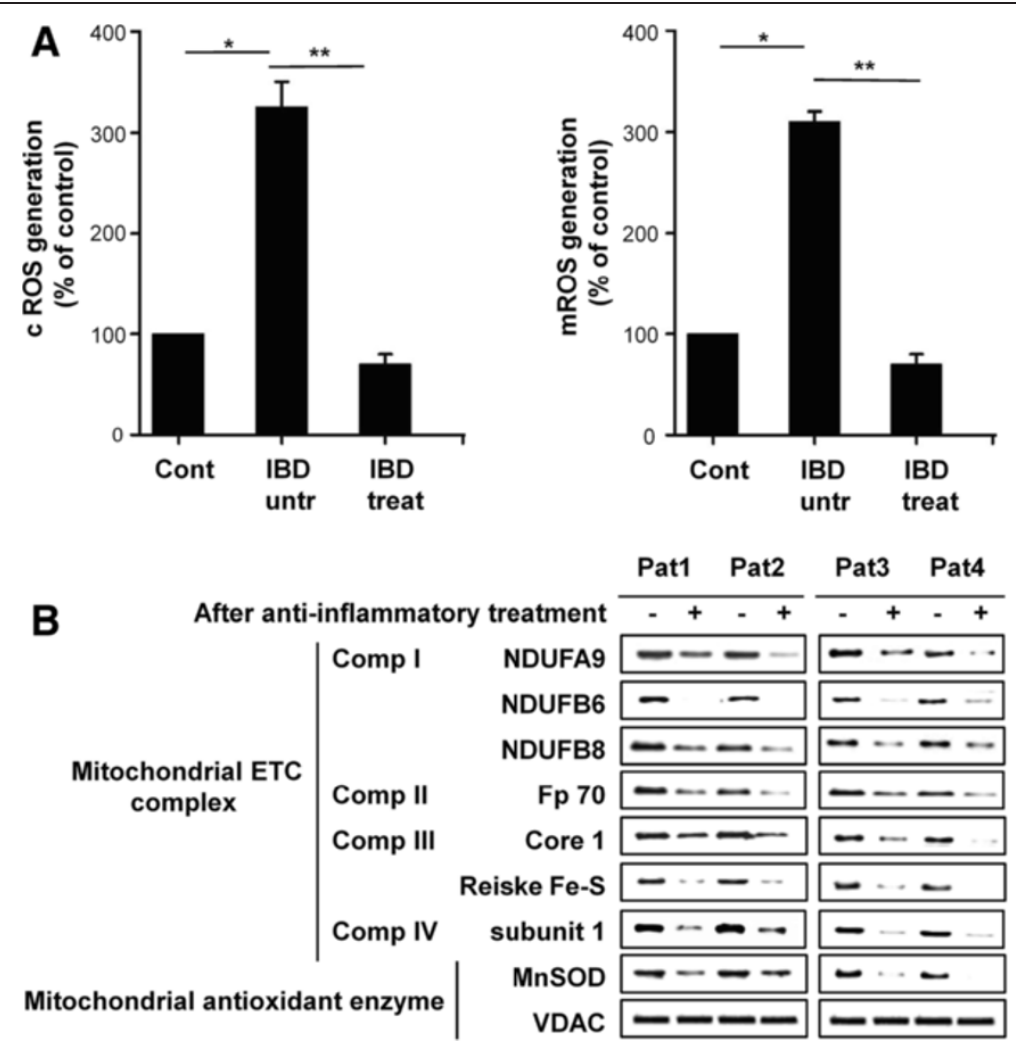

Figure 1 Mitochondrial reactive oxygen species generation in patients with inflammatory bowel disease. (A) Intracellular $\mathrm{H}_{2} \mathrm{O}_{2}$ and mitochondrial peroxynitrate levels in mononuclear cells of patients with IBD before (IBD untr) and after treatment (IBD treat), compared with healthy volunteers (cont). Results are expressed as means \pm SE. ${ }^{*} P<0.003$, ${ }^{* *} P<0.001$. (B) Western blotting analysis of the expression patterns of various mtETC complex subunits from mitochondria isolated from peripheral blood MNC of patients. pat - patient. IBD, inflammatory bowel disease; mtETC, mitochondrial electron transport chain; MNC, mononuclear cells.

MitoQ attenuates mitochondrial injury and oxidative damage To demonstrate the effect of MitoQ on mitochondria during colitis, we first studied mitochondrial structural changes. Electron microscopy of the colon of control mice revealed good preservation of normal mitochondrial structure (Figure 3A, left). In colon tissue in DSS and DSS+dTPP-treated mice,the majority of mitochondria had alterations in size and matrix. In some mitochondria, the matrix totally disappeared and only the outer membrane remained. In others, the cristae were disorganized because of edema in the matrix (Figure 3A, middle). MitoQ treatment reduced the morphological and mitochondrial injury during colitis (Figure 3A, right). There was a significant increase of malondialdehyde formation (a marker of lipid peroxidation, brown staining) in the colon during colitis (Figure 3B, middle) and MitoQ dramatically reduced the malondialdehyde formation (Figure 3B, right). Colitis was also associated with increased mitochondrial nitrotyrosine formation in the colon, an index of peroxynitrate-mediated protein nitration (Figure 3C, middle). However, MitoQ was protective against nitrate damage of the colon during colitis, as shown in Figure 3C (right). These data reveal that
MitoQ protects mitochondria and reduces oxidative damage in the colon of mice with DSS-induced colitis.

\section{MitoQ inhibits caspase-1 activation through suppression} of TXNIP binding to NLRP3 during colitis

To clarify the mechanism of MitoQ in attenuation of colitis, we investigated the function of the NLRP3 inflammasome. The NLRP3 inflammasome comprises adaptor proteins ACS and caspase-1. It isknown that TXNIP binds to the leucine-rich repeat domain of NLRP3 and activates the inflammasome during oxidative stress [20]. TXNIP binds to TRX and negatively regulates its redox function in resting cells [36]. Oxidized TRX during oxidative stress is dissociated from the TXNIPTRX complex, and leads to the interaction of TXNIP with NLRP3. Therefore, we hypothesized that binding of TXNIP to NLRP3 activates the inflammasome, which causes autocleavage of caspase- 1 and the release of mature cytokines IL-1 beta and IL-18 during colitis. Western blotting analysis revealed that expression of the inflammasome complex proteins such as NLRP3 and ASC are not changed during colitis, but procaspase- 1 is increased in 


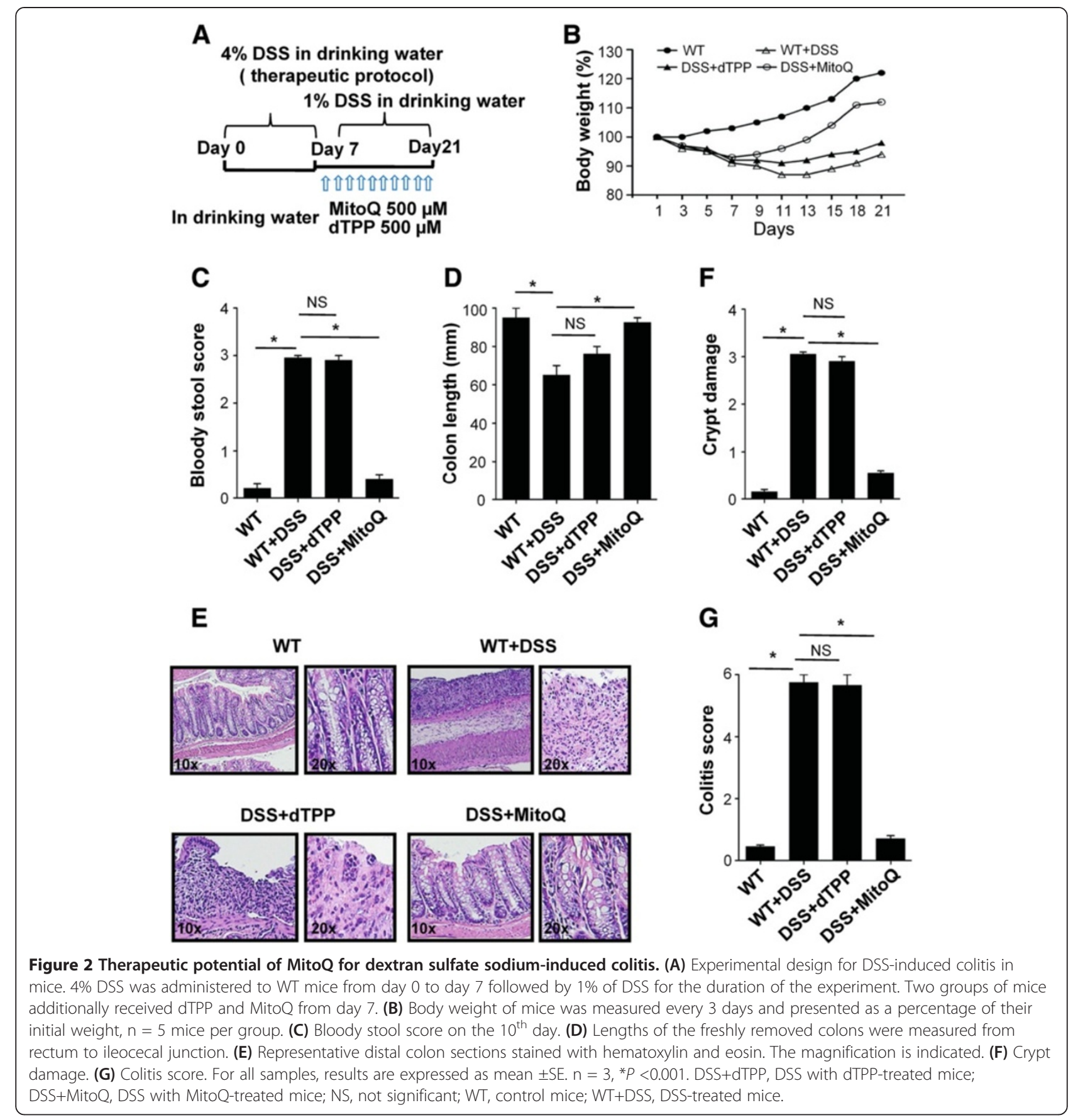

its expression and cleaved into caspase-1 in DSS- and DSS+dTPP-treated mice. However, procaspase-1 was not cleaved in control and MitoQ-treated mice (Figure 4A). Next, we performed co-IP to check the interaction between TXNIP and NLRP3, and revealed that TXNIP is dissociated from TRX in DSS- and DSS+dTPPtreated mice (Figure 4B). During colitis, the dissociated TXNIP was bound to NLRP3, and this interaction was blocked by MitoQ treatment (Figure 4C). To gain more insight into the mechanism of oxidative stress-induced colitis, we isolated mouse peritoneal macrophages and measured mitochondrial ROS levels. Macrophages of DSS+MitoQ-treated mice released lower levels of ROS compared with macrophages of DSS - and DSS+dTPPtreated mice (Figure 4D). Therefore, we concluded that activation of NLRP3 inflammasome during colitis is dependent on the interaction of TXNIP and NLRP3, and that this activation is mediated by mtROS. 

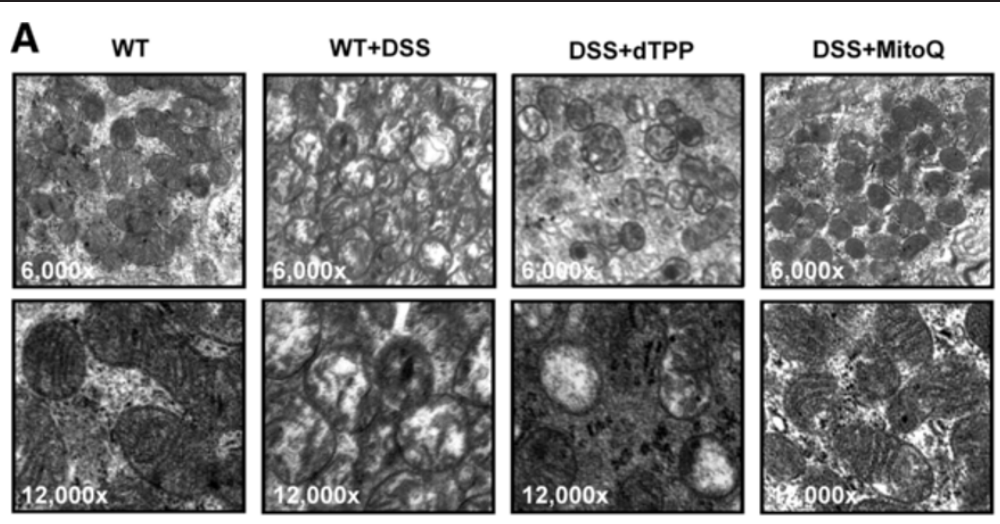

B
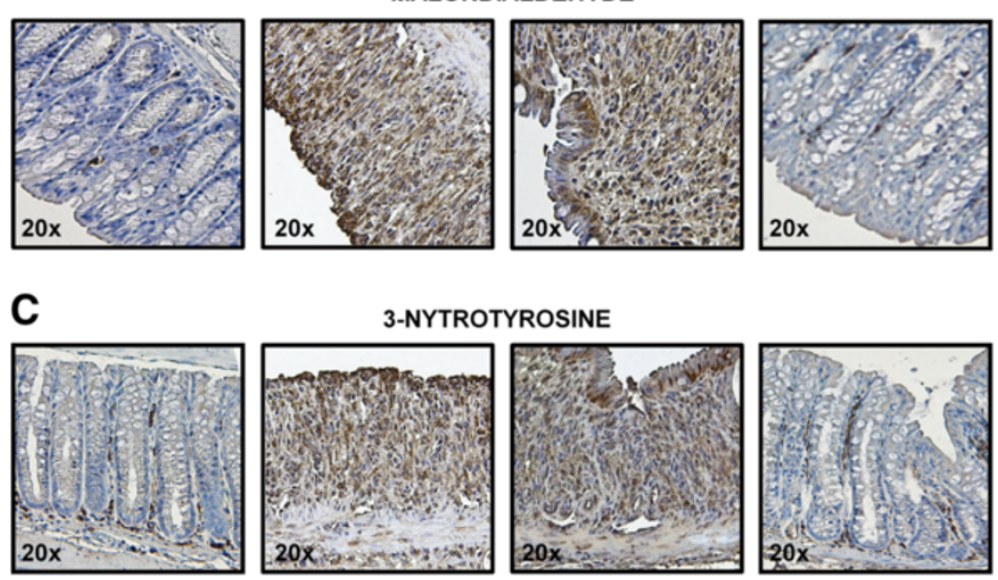

Figure 3 MitoQ attenuates mitochondrial alteration and oxidative damage during DSS-induced colitis. (A) Representative transmission electron micrographs of colon. The magnification is indicated. Similar histological profiles were seen in three separate colons per group.

(B) Sections of colonic tissues were subjected to immunohistochemical analysis with an antibody against malondialdehyde. The magnification is indicated. (C) Sections of colonic tissues were subjected to immunohistochemical analysis with an antibody against 3-nitrotyrosine staining. The magnification is indicated.

MitoQ suppresses increased levels of pro-inflammatory cytokines IL-1 beta and IL-18 during colitis

We next asked whether an activated inflammasome leads to enhanced release of IL-1 beta and IL-18 during colitis. Release of the active inflammatory cytokines IL-1 beta and IL-18 is mediated by a two-step process: first, recognition of pro-inflammatory signals by pattern recognition receptors on host cells and activation of pro-IL-1 beta and pro-IL-18 promoters; second, activation of the inflammasome by danger signals, resulting in activation of caspase- 1 and cleavage of pro-IL-1 beta and pro-IL-18 [37]. Therefore, we evaluated how MitoQ affects the release of these cytokines in colon homogenates. Levels of IL-1 beta and IL-18 were significantly higher in DSS- and DSS+dTPP-treated mice than in control and DSS+MitoQtreated mice, suggesting that MitoQ suppresses the release of these cytokines (Figure 5A,B). Furthermore, the mRNA levels of IL-1 beta and IL-18 were higher in DSS- and DSS+dTPP-treated mice, but suppressed with MitoQ treatment (Figure 5C). Lastly, western blotting analysis demonstrated the increased level of cleaved forms of caspase-1, IL-1 beta and IL-18 in the colon of DSS- and DSS+dTPP-treated mice, but the decreased cleavage in control and DSS+MitoQ-treated mice (Figure 5D). These data clearly demonstrate that MitoQ not only suppresses release of the active forms of IL-1 beta and IL-18, but also their transcriptional up-regulation.

\section{MitoQ decreases the levels of IL-1 beta and IL-18 in a human} macrophage cell line

Finally, we investigated the in vitro effect of MitoQ on IL-1 beta and IL-18 production in a human macrophagelike cell line, THP-1. ELISA analysis revealed that MitoQ dose-dependently reduces the release of these cytokines whereas it is induced by $\mathrm{H}_{2} \mathrm{O}_{2}$ and ATP (Figure 6A,B). Furthermore, co-IP studies revealed that TXNIP is dissociated from TRX and binds to NLRP3, and this interaction is blocked by MitoQ treatment (Figure 6C). Lastly, MitoQ also suppressed mtROS generation in a dose-dependent manner (Figure 6D). These results further confirmed the 


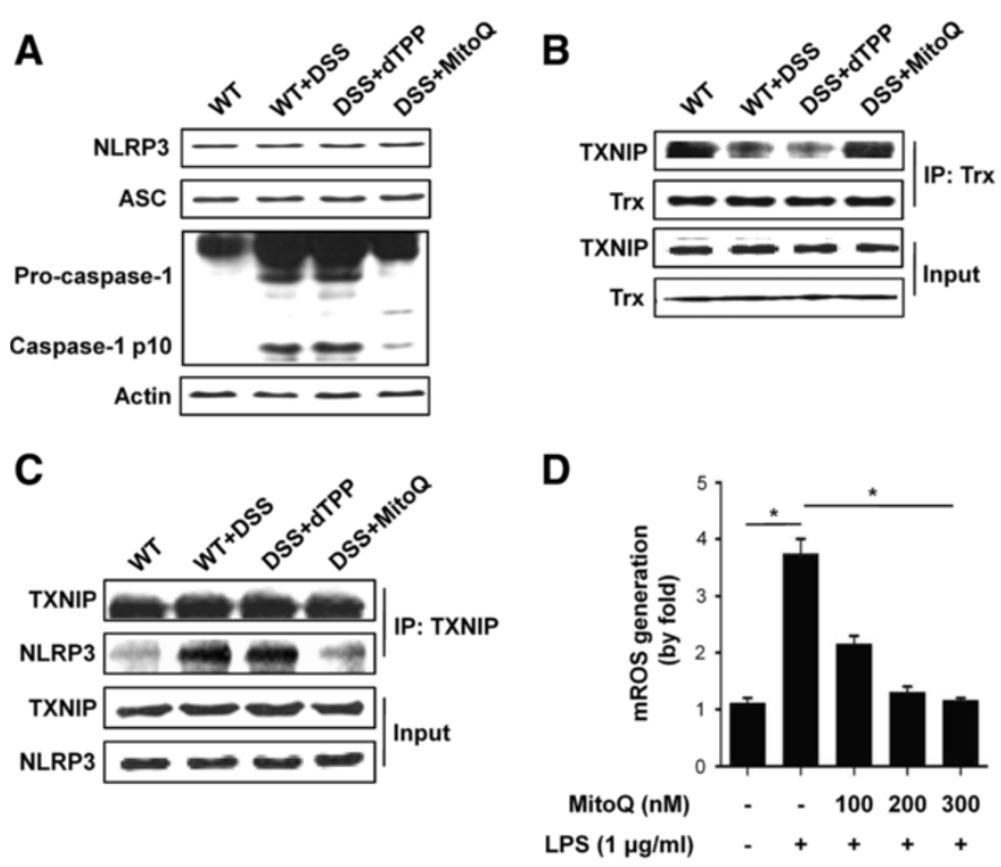

Figure 4 MitoQ inhibits caspase-1 activation through suppression of TXNIP binding to NLRP3 during colitis. (A) Western blotting analysis reveals expression of the NLRP3 inflammasome components in mouse colon homogenates. (B) Dissociation of the TXNIP-TRX complex upon MitoQ treatment, as revealed by co-immunoprecipitation. (C) Co-immunoprecipitation and western blotting analysis identify the interaction of TXNIP with NLRP3. IP, immunoprecipitation; input of cell extract without immunoprecipitation ensures equal loading. (D) Effect of MitoQ on mtROS production in peritoneal macrophages. Results are expressed as mean \pm SE. $n=5$. ${ }^{*} \mathrm{P}<0.01$.
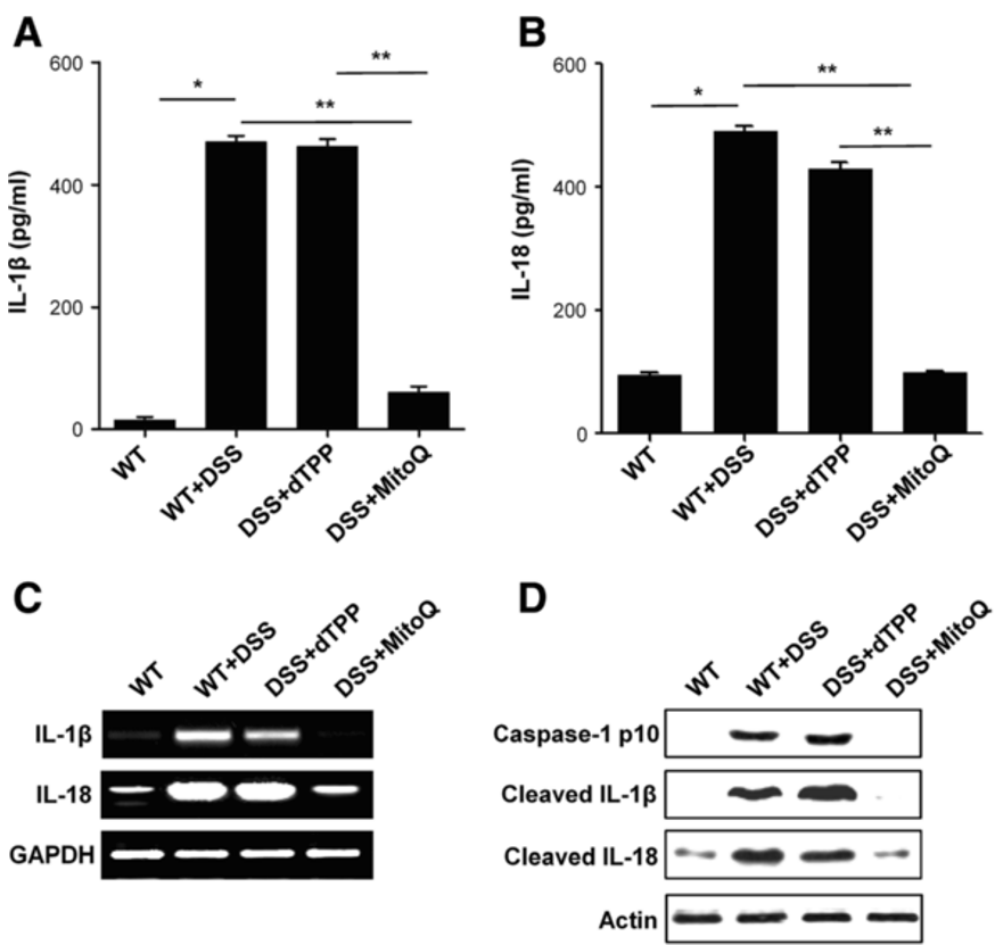

Figure 5 MitoQ suppresses caspase-1-mediated IL-1 beta and IL-18 release during colitis. ELISA assay for (A) IL-1 beta or (B) IL-18 were performed in colon homogenates. Results are expressed as mean \pm SE. $n=5$. ${ }^{*} P<0.001$, ${ }^{* *} P<0.01$. (C) mRNA expression levels of IL-1 beta and IL-18 in colon tissue were examined by RT-PCR. (D) Cleavages of caspase-1, IL-1 beta and IL-18 were analyzed by western blotting analysis in colon homogenates. 

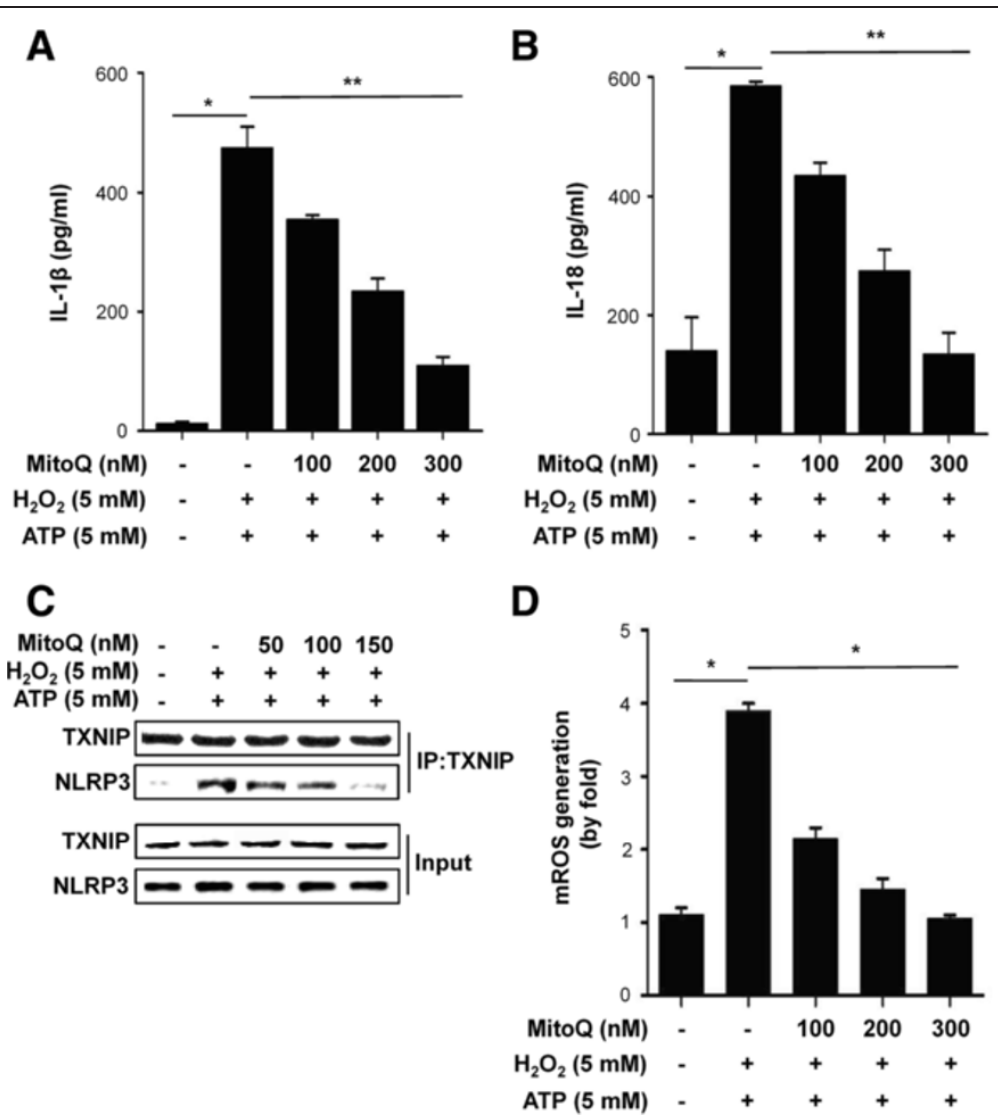

Figure 6 Effect of MitoQ on human THP-1 cells. (A) IL-1 beta and (B) IL-18 release in response to $\mathrm{H}_{2} \mathrm{O}_{2}$ or ATP were analyzed by ELISA. Results are expressed as mean $\pm S E$. $n=5,{ }^{*} P<0.001$. (C) The interaction between TXNIP and NLRP3 was examined by co-IP and western blotting analysis. (D) mtROS production in THP-1 cells. Cells were differentiated for 24 hours with $100 \mathrm{nM}$ phorbol 12-myristate 13-acetate. Results are expressed as mean \pm SE. ${ }^{*} P<0.001$.

potential of MitoQ for the treatment of acute colonic injury by reducing oxidative stress and inflammatory cytokines.

\section{Discussion}

Here, we for the first time show that administration of MitoQ decreases the severity of DSS-induced colitis in mice. In addition, scavenging mtROS by MitoQ resulted in a significant decrease of IL-1 beta and IL-18 in DSSinduced colitis. Consequently, our results provide insights into the role of mtROS in the pathogenesis of IBD, and suggest that MitoQ may have therapeutic potential as a new treatment for human IBD.

Oxidative injury induced by increased ROS levels has been demonstrated in patients with IBD and in experimental animals [21]. Also, a randomized controlled trial reported that supplementation of antioxidants resulted in significant clinical improvement of patients with UC [38], indicating that ROS may have a causative role in IBD. By contrast, other randomized controlled trials showed that antioxidant supplementation has no effect on activity of the disease. The reasons for this discrepancy in patients with IBD remain unknown. Since the treatment outcomes of antioxidants are affected by several factors including dosage, duration, phase of the disease, and antioxidant potency $[39,40]$, it may not be easy to clarify reasons for the contrasting results in clinical trials. A number of different cellular sources of ROS such as NADPH oxidase, inducible nitric oxide synthase, myeloperoxidase and xanthine oxidase have already been reported [41,42]. Here, we propose that mitochondria are the major source of ROS generation in IBD, and thus targeting mtROS may be important for understanding the therapeutic efficacy of antioxidants in patients with IBD. The reasons are as follows: first, we revealed that mtROS generation are significantly increased and expression levels of mtETC components are altered in the MNC of patients with IBD, all of which can be normalized after treatment with standard medications (Figure 1); second, we revealed that ROS levels and oxidative injury are increased in DSS-induced mouse colitis, but suppressed by treatment with MitoQ (Figures 3B,C and 4D); finally, other reports also suggested that mitochondrial alterations are important for IBD and CD, including the morphological changes of mitochondria in enterocytes of patients with IBD [43], 
the inhibited mitochondrial membrane potential in immune peripheral cells of patients with $C D$, and the functional defects at complex III and IV in isolated muscle mitochondria [23]. In addition, there are many evidences for a role of mtROS in hypoxia during inflammation [44]. Mucosal inflammation including vasculitis, vasoconstriction, thrombosis and edema contributes to inflammatory hypoxia in the intestine. Adaptation to hypoxia relies on the hypoxia-inducible factor, which in turn contributes to the induction of mucosal barrier genes $[45,46]$. But hypoxia also leads to increased expression of pro-inflammatory mediators $[47,48]$ and increased generation of mtROS [49], and could promote tumor growth [50,51]. Although physiological level of ROS is important for hypoxiainducible factor stabilization and phagocytosis, ROS are also considered to be second messengers for mucosal injury during IBD. In addition, inhibition of mtROS resulted in restoration of regulatory $\mathrm{T}$ cells induction [52]. These findings suggest that prolonged hypoxia can drive a robust inflammatory response that contributes to hypoxia-induced inflammation. Therefore, suppressing overgenerated mtROS might help to attenuate intestinal inflammation by reducing hypoxia and controlling $\mathrm{T}$ cell activation.

MitoQ is a well-established mitochondria-targeted antioxidant, and consists of a lipophilic TPP cation covalently linked to ubiquinone, which is the active antioxidant moiety of coenzyme Q. The adsorbed MitoQ in the mitochondrial inner membrane acts as an antioxidant and ubiquinone is rapidly reduced to its active ubiquinol form by complex II. MitoQ shows good pharmacokinetic behavior and was safely administered as a daily oral tablet to patients for a year in phase 2 trials [53]. Furthermore, it has been shown to have good antioxidative, anti-inflammatory and anti-apoptotic effects in many in vivo and in vitro studies [24-29]. In this study, we showed that MitoQ significantly improves clinical and histological changes in the DSSinduced mouse model of colitis (Figure 2A-G) by reducing oxidative stress and restoring mitochondrial alterations (Figure 3). These results suggest that mtROS may play an important role in IBD and indicate that MitoQ is a promising candidate for treatment of human IBD.

IL-1 beta and IL-18 are members of the IL-1 family of cytokines, which play major roles in the pathogenesis of IBD. Inflammatory cytokine IL-18 induces IL-1 beta, TNF- $\alpha$ and IFN- $\gamma$, and thus leads to severe gut inflammation [54]. IL-1 beta increases intestinal permeability [55] and promotes Th17 responses in the gut [10]. Such roles for IL-1 beta and IL-18 in IBD are supported by several studies. For example, it was reported that blockage of IL-1 beta [56,57] or neutralization of IL-18 $[58,59]$ reduces intestinal inflammation. Additionally, homozygous knock-out of NLRP3 and caspase-1 genes, or inhibition of caspase-1 by a specific inhibitor, protects mice from DSS-induced colitis $[16,17,60,61]$. The precursors of IL-1 beta and IL-18 are cleaved and activated by the cytosolic caspase-1 activating NLRP3 inflammasome, whose physiological activation may be critical in the maintenance of intestinal homeostasis. However, excessive activation of NLRP3 inflammasome leads to severe pathology. NLRP3 inflammasome activation is mediated by ROS via the ROS-sensitive ligand, TXNIP [20]. ROS induce the dissociation of TXNIP from TRX and allow TXNIP to bind

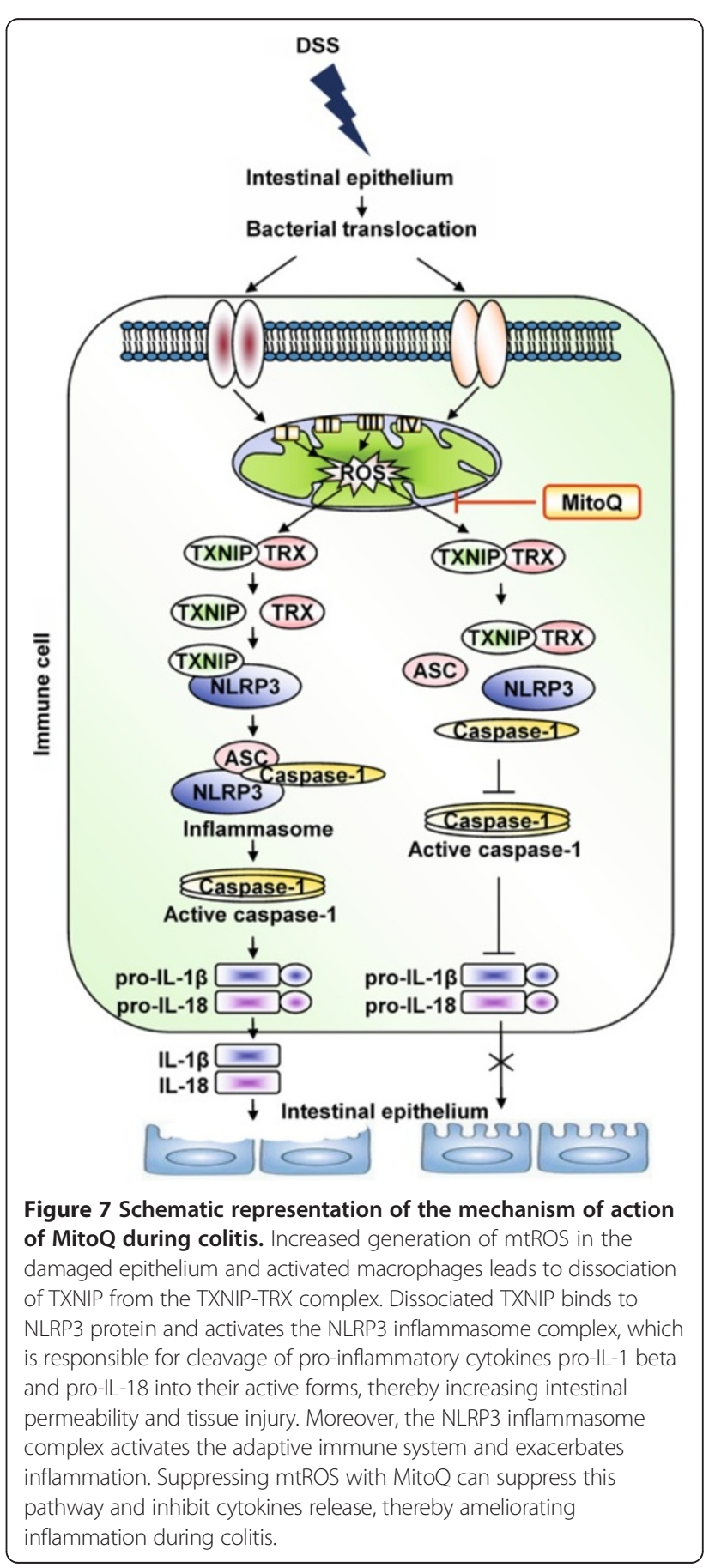


NLRP3. Although there is still controversy about the source of ROS responsible for NLRP3 inflammasome activation, our results suggest that mtROS are responsible for its activation. Consistent with this, recent studies revealed that inflammasome activation was observed in mice lacking NADPH oxidase subunits, and in patients with chronic granulomatous disease characterized by defects in NADH-oxidase subunits [62]. In the present study, we showed that MitoQ suppresses ROS-promoted dissociation of TXNIP from TRX, inhibits the interaction between TXNIP and NLRP3 (Figure 4), and significantly decreases levels of IL-1 beta and IL-18 in the colons of mice with DSS-induced colitis (Figure 5A,B). Furthermore, in vitro studies demonstrated that MitoQ also suppresses the release of IL-1 beta and IL-18 from human THP-1 cells (Figure 6A,B).

Finally, we conclude that overgeneration of mtROS during IBD leads to increase of inflammatory cytokines IL-1 beta and IL-18 via activation of the NLRP3 inflammasome. Active inflammatory cytokines increase intestinal permeability, tissue injury and decreasing mtROS with MitoQ can suppress this pathway and ameliorate inflammation during colitis (Figure 7).

We here used DSS-induced acute colitis, because it is one of the easiest, time- and cost-saving animal models. Actually, DSS has a direct toxic effect on colonic epithelium leading to a leaky tight junction and bacterial translocation. Therefore, this animal model may reflect an acute injury model rather than an inflammatory disease, indicating that it has a limitation to be used as a good IBD model [63]. Currently, more than 60 animal models are available for the study of IBD, but no individual model can fully reflect human IBD [64,65]. In some cases, investigators have used IL-10 knock-out or TNF (ARE)deleted mice to study the mechanisms of IBD pathogenesis [66-69]. We have first shown the therapeutic effect of MitoQ on IBD using the DSS-induced acute colitis model. To clarify MitoQ effect on IBD more clearly, additional tests will be needed in other well-established animal models such as IL-10 knock-out mice. If carefully designed studies show the positive effect of MitoQ on IBD treatment in diverse animal models, MitoQ may ultimately be tested in human patients with IBD.

\section{Conclusion}

We suggest that mtROS are an important causative factor in the pathogenesis of IBD. We showed that MitoQ ameliorates acute colonic injury in a mouse model of colitis not only by its antioxidative effects but also by anti-inflammatory effects that suppress the maturation of pro-inflammatory cytokines IL-1 beta and IL-18. Considering the potent protective role of MitoQ in an experimental model of colitis and its proven safety in human clinical trials, MitoQ is a possible therapeutic molecule for the treatment of acute phases of IBD.

\section{Additional file}

Additional file 1: Table S1. Medications for patients with IBD.

\section{Abbreviations}

ASC: Apoptosis-associated speck-like protein containing a CARD; CD: Crohn's disease; DCF-DA: Dichlorofluorescein-diacetate; DSS: Dextran sulphate sodium; dTPP: Decyltriphenylphosphonium bromide; ELISA: Enzyme-linked immunosorbent assay; Foxp3: Forkhead box p3; IBD: Inflammatory bowel disease; IFNY: Interferon gamma; IL: Interleukin; IP: Immunoprecipitation; MNC: Mononuclear cell; mtETC: Mitochondrial electron transport chain; mtROS: Mitochondrial reactive oxygen species; PBS: Phosphate-buffered saline; ROS: Reactive oxygen species; RT-PCR: Reverse transcription polymerase chain reaction; SE: Standard error; TNFa: Tumor necrosis factor alpha; TPP: Triphenylphosphonium; TRX: Thioredoxin; TXNIP: Thioredoxin interacting protein; UC: Ulcerative colitis; WT: Wild type.

\section{Competing interests}

MPM is on the scientific advisory board of Antipodean Pharmaceuticals, which is developing MitoQ as a therapy. All other authors declare that they have no competing interests.

\section{Authors' contributions}

AD, SSK: study concept and design; AD, SL, HJK: acquisition of data; AD, SL, SSK: analysis and interpretation of data; $A D$, SSK: drafting of the manuscript; $A D, J K R, S L, A J, M N N, J H, K S Y, H J K, J H P, M P M, S S K$ : critical revision of the manuscript for intellectual content; MPM: material support; SSK: study supervision. All authors read and approved the final manuscript.

\section{Acknowledgements}

This work was supported by the National Research Foundation of Korea (NRF) grant funded by the Korean government (MEST) (NO.20120009380) to SSK.

\section{Author details}

${ }^{1}$ Department of Biochemistry and Molecular Biology, School of Medicine, Kyung Hee University, Seoul 130-701, Republic of Korea. ${ }^{2}$ Division of Gastroenterology, Department of Internal Medicine, School of Medicine, Kyung Hee University, Seoul 130-701, Republic of Korea. ${ }^{3}$ Department of Pathology, School of Medicine, Kyung Hee University, Seoul 130-701, Republic of Korea. ${ }^{4}$ MRC Mitochondrial Biology Unit, Hills Road, Cambridge CB2 OXY, UK

Received: 5 April 2013 Accepted: 8 July 2013

Published: 6 August 2013

\section{References}

1. Kethu SR: Extraintestinal manifestations of inflammatory bowel diseases. J Clin Gastroenterology 2006, 40:467-475.

2. Guidi L, Pugliese D, Armuzzi A: Update on the management of inflammatory bowel disease: specific role of adalimumab. Clin Exp Gastroenterol 2011, 4:163-172.

3. Naija N, Karoui S, Serghini M, Kallel L, Boubaker J, Filali A: Management of failure of infliximab in inflammatory bowel disease. Tunis Med 2011, 89:517-521.

4. Molodecky NA, Soon IS, Rabi DM, Ghali WA, Ferris M, Chernoff G, Benchimol El, Panaccione R, Ghosh S, Barkema HW, Kaplan GG: Increasing incidence and prevalence of the inflammatory bowel diseases with time, based on systematic review. Gastroenterology 2012, 142:46-54.

5. Maloy KJ, Powrie F: Intestinal homeostasis and its breakdown in inflammatory bowel disease. Nature 2011, 474:298-306.

6. Dinarello CA: Immunological and inflammatory functions of the interleukin-1 family. Annu Rev Immunol 2009, 27:519-550.

7. Chung Y, Chang SH, Martinez GJ, Yang XO, Nurieva R, Kang HS, Ma L, Watowich SS, Jetten AM, Tian Q, Dong C: Critical regulation of early Th17 cell differentiation by interleukin-1 signaling. Immunity 2009, 30:576-587.

8. Clambey ET, McNamee EN, Westrich JA, Glover LE, Campbell EL, Jedlicka P, de Zoeten EF, Cambier JC, Stenmark KR, Colgan SP, Eltzschig HK: Hypoxia-inducible 
factor-1 alpha-dependent induction of FoxP3 drives regulatory T-cell abundance and function during inflammatory hypoxia of the mucosa. Proc Natl Acad Sci U S A 2012, 109:E2784-E2793.

9. Ziegler SF, Buckner JH: FOXP3 and the regulation of Treg/Th17 differentiation. Microbes Infect 2009, 11:594-598.

10. Coccia M, Harrison OJ, Schiering C, Asquith MJ, Becher B, Powrie F, Maloy $\mathrm{KJ}$ : IL-1 beta mediates chronic intestinal inflammation by promoting the accumulation of IL-17A secreting innate lymphoid cells and CD4 (+) Th17 cells. J Exp Med 2012, 209:1595-1609.

11. Mahida YR, Wu K, Jewell DP: Enhanced production of interleukin 1-beta by mononuclear cells isolated from mucosa with active ulcerative colitis of Crohn's disease. Gut 1989, 30:835-838.

12. McAlindon ME, Hawkey CJ, Mahida YR: Expression of interleukin 1 beta and interleukin 1 beta converting enzyme by intestinal macrophages in health and inflammatory bowel disease. Gut 1998, 42:214-219.

13. Guimbaud R, Bertrand V, Chauvelot-Moachon L, Quartier G, Vidon N, Giroud JP, Couturier D, Chaussade S: Network of inflammatory cytokines and correlation with disease activity in ulcerative colitis. Am J Gastroenterol 1998, 93:2397-2404.

14. Schoultz I, Verma D, Halfvarsson J, Törkvist L, Fredrikson M, Sjöqvist U, Lördal M, Tysk C, Lerm M, Söderkvist P, Söderholm JD: Combined polymorphisms in genes encoding the inflammasome components NALP3 and CARD8 confer susceptibility to Crohn's disease in Swedish men. Am J Gastroentero/ 2009, 104:1180-1188.

15. Schroder K, Tschopp J: The inflammasome. Cell 2010, 140:821-832.

16. Bauer C, Duewell P, Mayer C, Lehr HA, Fitzgerald KA, Dauer M, Tschopp J, Endres S, Latz E, Schnurr M: Colitis induced in mice with dextran sulfate sodium (DSS) is mediated by the NLRP3 inflammasome. Gut 2010, 59:1192-1199.

17. Bauer C, Duewell P, Lehr HA, Endres S, Schnurr M: Protective and aggravating effects of Nlrp3 inflammasome activation in IBD models: influence of genetic and environmental factors. Dig Dis 2012, 30(1):82-90.

18. Shimada K, Crother TR, Karlin J, Dagvadorj J, Chiba N, Chen S, Ramanujan VK, Wolf AJ, Vergnes L, Ojcius DM, Rentsendorj A, Vargas M, Guerrero C, Wang Y, Fitzgerald KA, Underhill DM, Town T, Arditi M: Oxidized mitochondrial DNA activates the NLRP3 inflammasome during apoptosis. Immunity 2012, 36:401-414.

19. Zhou R, Yazdi AS, Menu P, Tschopp J: Role for mitochondria in NLRP3 inflammasome activation. Nature 2011, 469:221-225.

20. Zhou R, Tardivel A, Thorens B, Choi I, Tschopp J: Thioredoxin-interacting protein links oxidative stress to inflammasome activation. Nature Immunol 2010, 11:136-140.

21. Pavlick KP, Laroux FS, Fuseler J, Wolf RE, Gray L, Hoffman J, Grisham MB: Role of reactive metabolites of oxygen and nitrogen in inflammatory bowel disease. Free Radic Biol Med 2002, 33:311-322.

22. Beltrán B, Nos P, Dasí F, Iborra M, Bastida G, Martínez M, O'Connor JE, Sáez G, Moret I, Ponce J: Mitochondrial dysfunction, persistent oxidative damage, and catalase inhibition in immune cells of naive and treated Crohn's disease. Inflamm Bowel Dis 2010, 16:76-86.

23. Restivo NL, Srivastava MD, Schafer IA, Hoppel CL: Mitochondrial dysfunction in a patient with Crohn's disease: possible role in pathogenesis. J Pediatr Gastroenterol Nutr 2004, 38:534-538.

24. Mukhopadhyay P, Horváth B, Zsengellèr Z, Bátkai S, Cao Z, Kechrid M, Holovac E, Erdèlyi K, Tanchian G, Liaudet L, Stillman IE, Joseph J, Kalyanaraman B, Pacher $P$ : Mitochondrial reactive oxygen species generation triggers inflammatory response and tissue injury associated with hepatic ischemia-reperfusion: therapeutic potential of mitochondrially targeted antioxidants. Free Radic Biol Med 2012, 53:1123-1138.

25. Graham D, Huynh NN, Hamilton CA, Beattie E, Smith RA, Cochemé HM, Murphy MP, Dominiczak AF: Mitochondria-targeted antioxidant MitoQ10 improves endothelial function and attenuates cardiac hypertrophy. Hypertension 2009, 54:322-328.

26. Supinski GS, Murphy MP, Callahan LA: MitoQ administration prevents endotoxin-induced cardiac dysfunction. Am J Physiol Regul Integr Comp Physiol 2009, 297:R1095-R1102.

27. Chacko BK, Srivastava A, Johnson MS, Benavides GA, Chang MJ, Ye Y, Jhala N, Murphy MP, Kalyanaraman B, Darley-Usmar VM: The mitochondria-targeted ubiquinone MitoQ decreases ethanol-dependent micro and macro hepatosteasis. Hepatology 2011, 54:153-163.

28. Lowes DA, Thottakam BM, Webster NR, Murphy MP, Galley HF: The mitochondria-targeted antioxidant MitoQ protects against organ damage in a lipopolysaccharide-peptidoglycan model of sepsis. Free Radic Biol Med 2008, 45:1559-1565.

29. Gane EJ, Weilert F, Orr DW, Keogh GF, Gibson M, Lockhart MM, Frampton CM, Taylor KM, Smith RA, Murphy MP: The mitochondria-targeted anti-oxidant mitoquinone decreases liver damage in a phase II study of hepatitis $C$ patients. Liver Int 2010, 30:1019-1026.

30. Lim S, Won H, Kim Y, Jang M, Jyothi KR, Kim Y, Dandona P, Ha J, Kim SS: Antioxidant enzymes induced by repeated intake of excess energy in the form of high-fat, high-carbohydrate meals are not sufficient to block oxidative stress in healthy lean individuals. Br J Nutr 2011, 106:1544-1551.

31. Lee S, Tak E, Lee J, Rashid MA, Murphy MP, Ha J, Kim SS: Mitochondrial $\mathrm{H} 2 \mathrm{O} 2$ generated from electron transport chain complex I stimulates muscle differentiation. Cell Res 2011, 21:817-834.

32. Yan Y, Kolachala V, Dalmasso G, Nguyen H, Laroui H, Sitaraman SV, Merlin D: Temporal and spatial analysis of clinical and molecular parameters in dextran sodium sulfate induced colitis. Plos One 2009, 4(6):e6073-e6080.

33. Yotsuya S, Shikama H, Imamura M: Efficacy of the inflammatory cell infiltration inhibitor IS-741 on colitis induced by dextran sulfate sodium in the rat. Jpn J Pharmacol 2001, 87:151-157.

34. Adlam VJ, Harrison JC, Porteous CM, James AM, Smith RA, Murphy MP Sammut IA: Targeting an antioxidant to mitochondria decreases cardiac ischemia-reperfusion injury. FASEB J 2005, 19:1088-1095.

35. Hayakawa $Y$, Hirata $Y$, Nakagawa H, Sakamoto K, Hikiba Y, Otsuka M, ljichi H, Ikenoue T, Tateishi K, Akanuma M, Ogura K, Yoshida H, Ichijo H, Omata M, Maeda S: Apoptosis signal-regulating kinase 1 regulates colitis and colitis-associated tumorigenesis by the innate immune responses. Gastroenterology 2010, 138:1055-1067.

36. Nishiyama A, Matsui M, Iwata S, Hirota K, Masutani H, Nakamura H, Takagi Y, Sono H, Gon Y, Yodoi J: Identification of thioredoxin-binding protein -2/vitamin D3 upregulated protein 1 as a negative regulator of thioredoxin function and expression. J Biol Chem 1999, 274:21645-21650

37. van de Veerdonk FL, Netea MG, Dinarello CA, Joosten LA: Inflammasome activation and IL-1 beta and IL-18 processing during infection. Trends Immunol 2011, 32:110-116.

38. Seidner DL, Lashner BA, Brzezinski A, Banks PL, Goldblum J, Fiocchi C, Katz J, Lichtenstein GR, Anton PA, Kam LY, Garleb KA, Demichele SJ: An oral supplement enriched with fish oil, soluble fiber, and antioxidants for corticosteroid sparing in ulcerative colitis: a randomized, controlled trial. Clin Gastroenterol Hepatol 2005, 3:358-369.

39. Aghdassi E, Wendland BE, Steinhart AH, Wolman SL, Jeejeebhoy K, Allard JP: Antioxidant vitamin supplementation in Crohn's disease decreases oxidative stress: a randomized controlled trial. Am J Gastroenterol 2003, 98:348-353

40. Geerling BJ, Badart-Smook A, van Deursen C, van Houwelingen AC, Russel MG, Stockbrügger RW, Brummer RJ: Nutritional supplementation with N-3 fatty acids and antioxidants in patients with Crohn's disease in remission: effects on antioxidant status and fatty acid profile. Inflamm Bowel Dis 2000, 6:77-84.

41. Hausmann M, Spöttl T, Andus T, Rothe G, Falk W, Schölmerich J, Herfarth H, Rogler G: Subtractive screening reveals up-regulation of NADPH oxidase expression in Crohn's disease intestinal macrophages. Clin Exp Immunol 2001, 125:48-55.

42. Szanto I, Rubbia-Brandt L, Kiss P, Steger K, Banfi B, Kovari E, Herrmann F, Hadengue A, Krause KH: Expression of NOX1, a superoxide-generating NADPH oxidase, in colon cancer and inflammatory bowel disease. J Pathol 2005, 207:164-176.

43. Söderholm JD, Olaison G, Peterson KH, Franzén LE, Lindmark T, Wirén M, Tagesson C, Sjödahl R: Augmented increase in tight junction permeability by luminal stimuli in the non-inflamed ileum of Crohn's Disease. Gut 2002, 50:307-313.

44. Cash TP, Pan Y, Simon MC: Reactive oxygen species and cellular oxygen sensing. Free Radic Biol Med 2007, 43:1219-1225.

45. Eltzschig HK, Carmeliet P: Hypoxia and inflammation. N Engl J Med 2011, 364:656-665.

46. Eltzschig HK, Sitkovsky MV, Robson SC: Purinergic signaling during inflammation. N Engl J Med 2013, 368:1260.

47. Shah YM, Ito S, Morimura K, Chen C, Yim SH, Haase VH, Gonzalez FJ: Hypoxia-inducible factor augments experimental colitis through a MIF-dependent inflammatory signaling cascade. Gastroenterology 2008, 134:2036-2048 
48. Scortegagna M, Cataisson C, Martin RJ, Hicklin DJ, Schreiber RD, Yuspa SH, Arbeit JM: HIF-1alpha regulates epithelial inflammation by cell autonomous NFkB activation and paracrine stromal remodeling. Blood 2008, 111:3343-3354.

49. Lluis JM, Buricchi F, Chiarugi P, Morales A, Fernandez-Checa JC: Dual role of mitochondrial reactive oxygen species in hypoxia signaling: activation of nuclear factor-\{kappa\}B via c-SRC and oxidant-dependent cell death. Cancer Res 2007, 67:7368-7377.

50. Semenza GL: Defining the role of HIF-1 in cancer biology and therapeutics. Oncogene 2010, 29:625-634

51. Xue X, Taylor M, Anderson E, Hao C, Qu A, Greenson JK, Zimmermann EM, Gonzalez FJ, Shah YM: Hypoxia-inducible factor 2 alpha activation promotes colorectal cancer progression by dysregulation iron homeostasis. Cancer Res 2012, 72:2285-2293.

52. Kaminski MM, Sauer SW, Klemke CD, Süss D, Okun JG, Krammer PH, Gülow $\mathrm{K}$ : Mitochondrial reactive oxygen species control $\mathrm{T}$ cell activation by regulating IL-2 and IL-4 expression: mechanism of ciprofloxacinmediated immunosuppression. J Immunol 2010, 184:4827-4841.

53. Protect Study Group, Snow BJ, Rolfe FL, Lockhart MM, Frampton CM, O'Sullivan JD, Fung V, Smith RA, Murphy MP, Taylor KM: A double-blind, placebo-controlled study to assess the mitochondria-targeted antioxidant MitoQ as a disease modifying therapy in Parkinson's disease. Mov Disord 2010, 25:1670-1674.

54. Pagès $F$, Lazar $V$, Berger $A$, Danel $C$, Lebel-Binay $S$, Zinzindohoué $F$, Desreumaux P, Cellier C, Thiounn N, Bellet D, Cugnenc PH, Fridman WH: Analysis of interleukin-18, interleukin-1 converting enzyme (ICE) and interleukin-18-related cytokines in Crohn's disease lesions. Eur Cytokine Netw 2001, 12:97-104.

55. Al-Sadi R, Guo S, Dokladny K, Smith MA, Ye D, Kaza A, Watterson DM, Ma TY: Mechanism of interleukin-1beta induced-increase in mouse intestinal permeability in vivo. J Interferon Cytokine Res 2012, 32:474-484.

56. Thomas TK, Will PC, Srivastava A, Wilson CL, Harbison M, Little J, Chesonis RS, Pignatello M, Schmolze D, Symington J, Kilian PL, Thompson RC: Evaluation of an interleukin-1 receptor antagonist in the rat acetic acid-induced colitis model. Agents Actions 1991, 34:187-190.

57. Cominelli F, Nast CC, Duchini A, Lee M: Recombinant interleukin-1 receptor antagonist blocks the pro-inflammatory activity of endogenous interleukin-1 in rabbit immune colitis. Gastroenterology 1992, 103:65-71.

58. Sivakumar PV, Westrich GM, Kanaly S, Garka K, Born TL, Derry JM, Viney JL: Interleukin 18 is a primary mediator of the inflammation associated with dextran sulphate sodium induced colitis: blocking interleukin 18 attenuates intestinal damage. Gut 2002, 50:812-820.

59. Ten Hove T, Corbaz A, Amitai H, Aloni S, Belzer I, Graber P, Drillenburg P, van Deventer SJ, Chvatchko Y, Te Velde AA: Blockade of endogenous IL-18 ameliorates TNBS-induced colitis by decreasing local TNF-alpha production in mice. Gastroenterology 2001, 121:1372-1379.

60. Siegmund B, Lehr HA, Fantuzzi G, Dinarello CA: IL-1 beta-converting enzyme (caspase-1) in intestinal inflammation. Proc Natl Acad Sci U S A 2001, 98:13249-13254

61. Loher F, Bauer C, Landauer N, Schmall K, Siegmund B, Lehr HA, Dauer M, Schoenharting $M$, Endres S, Eigler A: The interleukin-1 beta-converting enzyme inhibitor pralnacasan reduces dextran sulfate sodium-induced murine colitis and T helper 1 T-cell activation. J Pharmacol Exp Ther 2004, 308:583-590.

62. Meissner F, Seger RA, Moshous D, Fischer A, Reichenbach J, Zychlinsky A Inflammasome activation in NADPH oxidase defective mononuclear phagocytes from patients with chronic granulomatous disease. Blood 2010, 116:1570-1573.

63. Ni J, Chen SF, Hollander D: Effects of dextran sulphate sodium on intestinal epithelial cells and intestinal lymphocytes. Gut 1996, 39:234-241.

64. Mizoguchi A: Animal models of inflammatory bowel disease. Prog Mol Biol Trans/ Sci 2012, 105:263-320.

65. Mizoguchi A, Mizoguchi E: Inflammatory bowel disease, past, present and future: lessons from animal models. J Gastroenterol 2008, 43:1-17.

66. Berg DJ, Zhang J, Weinstock JV, Ismail HF, Earle KA, Alila H, Pamukcu R, Moore S, Lynch RG: Rapid development of colitis in NSAID-treated IL-10-deficient mice. Gastroenterology 2002, 123:1527-1542.

67. Kühl AA, Pawlowski NN, Grollich K, Loddenkemper C, Zeitz M, Hoffmann JC: Aggravation of intestinal inflammation by depletion/deficiency of gammadelta T cells in different types of IBD animal models. J Leukoc Biol 2007, 81:168-175.
68. Huybers S, Apostolaki M, van der Eerden BC, Kollias G, Naber TH, Bindels RJ, Hoenderop JG: Murine TNF(DeltaARE) Crohn's disease model displays diminished expression of intestinal Ca2+ transporters. Inflamm Bowel Dis 2008, 14:803-811.

69. Hale LP, Greer PK: A novel murine model of inflammatory bowel disease and inflammation-associated colon cancer with ulcerative colitis-like features. PLoS One 2012, 7:e41797-e41808.

doi:10.1186/1741-7015-11-178

Cite this article as: Dashdorj et al.: Mitochondria-targeted antioxidant MitoQ ameliorates experimental mouse colitis by suppressing NLRP3 inflammasome-mediated inflammatory cytokines. BMC Medicine 2013 11:178.

\section{Submit your next manuscript to BioMed Central and take full advantage of:}

- Convenient online submission

- Thorough peer review

- No space constraints or color figure charges

- Immediate publication on acceptance

- Inclusion in PubMed, CAS, Scopus and Google Scholar

- Research which is freely available for redistribution 